Article

\title{
Food Quality, Sensory Attributes and Nutraceutical Value of Fresh "Osteen" Mango Fruit Grown under Mediterranean Subtropical Climate Compared to Imported Fruit
}

\author{
Giorgia Liguori $^{1, *(D)}$, Carla Gentile ${ }^{2}$ (D) Giuseppe Sortino ${ }^{1}$ (D) Paolo Inglese ${ }^{1}$ and \\ Vittorio Farina ${ }^{1}$ (D) \\ 1 Department of Agricultural, Food and Forest Sciences, Università degli Studi di Palermo, \\ viale delle Scienze ed. 4, 90128 Palermo, Italy; giuseppe.sortino@unipa.it (G.S.); \\ paolo.inglese@unipa.it (P.I.); vittorio.farina@unipa.it (V.F.) \\ 2 Department of Biological, Chemical and Pharmaceutical Sciences and Technologies (STEBICEF), \\ University of Palermo, Viale delle Scienze, 90128 Palermo, Italy; carla.gentile@unipa.it \\ * Correspondence: giorgia.liguori@unipa.it
}

Received: 26 February 2020; Accepted: 21 March 2020; Published: 2 April 2020

\begin{abstract}
Mango is a fruit with a very short shelf-life due to its rapid ripeness after harvest; it is high in B vitamins, contains some amounts of magnesium, calcium, zinc, and selenium and it is rich in soluble and insoluble fibers. In order to reach the European markets at proper marketable maturity, fruit from tropical countries are harvested at early maturity stage. Although this harvesting practice improves mango postharvest life, fruit reach the market with very low quality, especially in terms of taste. The present study was conducted to evaluate food quality, sensory attributes and nutraceutical value of "Osteen" fresh Mediterranean Italian mango fruit, and imported ones coming from tropical countries. Mango fruit imported from abroad were collected from 5 large-scale organized markets; fresh Italian mango fruit were harvested from a commercial orchard, at green- and mature-ripe stage. Imported and fresh Italian mango fruit were analyzed in terms of firmness, total soluble solids content, titratable acidity, flesh disorders, nutraceutical value, and sensory attributes. Mediterranean Italian mango fruit showed the best quality performances in terms of nutraceutical value and quality attributes. Sensorial analysis confirmed this behavior, these quality attributes, were perceived by the trained panel, that preferred fresh Mediterranean mango fruit.
\end{abstract}

Keywords: Mangifera indica; Italian mango production; quality attributes; bioactive compounds; sensory analysis

\section{Introduction}

Mango (Mangifera indica L.) is one of the major fruit crops in tropical and subtropical regions. Among tropical fruit, mango production is second behind bananas (more than 113 million tons) reaching 46 million tons [1] that are mostly shipped to foreign markets [2].

Mango production is mostly concentrated in India, China, Thailand, Indonesia, Philippines, Pakistan, and Mexico, but in recent decades, its cultivation has been spreading also outside the traditional geographical regions to Australia, Central, and South America, South-East Asia, Hawaii, Egypt, Israel, South Africa, and Europe, especially for export [3].

The favorable climate of the Mediterranean basin areas is suitable for mango cultivation, particularly in Egypt, Israel, Spain, and in Italy, especially in Sicily [4,5]. The Sicilian climatic conditions differ greatly from those of tropical mango-growing countries, indeed, the winter is mild 
and wet and the summer is hot and dry; due to those climatic conditions, in Sicily, the mango harvest window has been enlarged to six months (from June to November) [4].

Mango is a fruit with a relatively short shelf-life and is one of the most consumed fruits in the world. The most popular exported mango cultivars are "Kent", "Tommy Atkins", "Haden", and "Keitt"; less known cultivars such as "Ataulfo", "Amelie", "Francis", and "Osteen" are now being widely accepted all over the world [1,2].

A part of its sensorial attributes, mango fruit has high nutritional value. It is high in B vitamins, contains some amounts of magnesium, calcium, zinc, and selenium and it is rich in both soluble and insoluble fibers. In addition, mango fruit are an interesting source of antioxidant molecules, including phenolic compounds, and antioxidant vitamins such as carotenoids, and vitamin $C[6,7]$. The quality attributes of mango fruit, including nutritional and nutraceutical parameters, depends strongly on genotype, but pre-harvest and post-harvest factors are also important [8,9].

In order to reach distant markets, while simultaneously achieving optimum eating quality, mango fruit are usually picked at mature-green stage, firm, and green (physiologically mature), but before the onset of the climacteric rise; whereas fruits sent to local markets or air-shipped are harvested at mature-ripe stage $[10,11]$. If mango fruit are immature at harvest, they do not reach a high-quality eating standard when ripe, and hence, the differences between early and optimal fruit harvest are very important from a marketing point of view, in order to have the best quality and to reduce losses in the supply chain [12]. The ripening process in mature-green fruit takes within 9-14 days and includes starch to sugar conversion, decreased acidity and increased carotenoids and aroma volatiles; mature-ripe fruit shortly decline within 6 days at room temperature [13].

The largest import markets for fresh and processed tropical fruit belong to the European Union followed by the United States of America [14]; in recent decades, consumer demand for tropical fruit has increased, for several reasons, such as health consciousness, population growth of ethnic minorities in Europe and through international travel and global communication [15].

Several authors have investigated the complex interactions of different factors influencing consumers' choices and preferences in terms of fruit and vegetables, but only a few have focused on tropical fruit [16]. There is a lack of data in terms of food quality, nutraceutical value and sensory analysis on fresh Mediterranean Italian mango fruit compared to imported ones in Europe, as well as on taste sensing and consumer preference of Mediterranean mango production, which are described but not compared to imported mango production [17].

Appearance, freshness and peel color are relevant fruit quality parameters and play a significant role in consumer mango fruit acceptability and preference [18]. Generally, during ripening, mango varieties change color from green to yellow or orange, often showing a red blush [11]. The sensory profile of mango fruit, especially color, taste, aroma, and flavor, has a great impact on consumers' choices [8].

Nowadays, consumers are more interested in the role that foods have in maintaining and promoting health, therefore, nutraceutical value is important to determine fruit quality. Sensory experiences have a prevalent role in shaping consumers' satisfaction and, by implication, acceptance of tropical fruit with which they are unfamiliar [15]. Unfamiliarity with tropical fruit and the high prices are the principal barriers for consumption and purchase in Europe.

The present study was conducted to evaluate food quality, sensory attributes and nutraceutical value of fresh "Osteen" mango fruit grown under Mediterranean subtropical climate compared to imported fruit. The study was conducted to verify if Southern Italy mango fruit production can reach the high-quality standard and offer interesting export potential for fresh fruit, due to its closeness to other EU countries 


\section{Materials and Methods}

\subsection{Experimental Design}

"Osteen" mango fruit produced in Italy, under Mediterranean subtropical climate, was harvested from a commercial orchard, located at Furiano, province of Messina (Sicily, Italy; $38^{\circ} 3^{\prime} \mathrm{N}, 14^{\circ} 33^{\prime} \mathrm{E} ; 5 \mathrm{~m}$ a.s.l.). Six uniform 11-year-old trees, grafted on Gomera-3 rootstock, trained to a globe shape, were selected. Fruit ( $n=180,20$ fruits $\times 9$ trees) were hand-picked at mature-green (GR) and mature-ripe (MR) stage, suitable for the fresh fruit market. Fruit morphological characteristics such as shape, from oval to round, or skin color were taken into account, according to the cultivar, to assess the level of ripeness $[5,18,19]$. Ninety fruits were used for sensory and physicochemical analysis; ninety fruits were used to extract the pulp (after washing and peeling), which was immediately frozen in liquid nitrogen and then stored at $-80{ }^{\circ} \mathrm{C}$ and used for the nutraceutical evaluation within one month. Immediately after harvest MR fruit were evaluated or were frozen, mature-green fruit were stored at room temperature $\left(20^{\circ} \mathrm{C}\right)$ for $4-8$ days, until they reached ready-to-eat maturity (MR) and then were submitted to analysis or were frozen.

Immediately after harvest, the weight, firmness, total soluble solids content (TSS) and titratable acidity (TA) were measured on 30 mango fruits.

Osteen mango fruit imported from abroad and grown under tropical climate were collected from 5 large-scale organized distribution markets. On the same day, fruit with external injuries were removed, while the rest were presorted ( $n=180,18$ replicates of 10 fruit), using nondestructive (color index) and destructive (firmness) criteria, into GR and MR categories to facilitate the qualitative and descriptive analysis. A total of 90 fruits were used for sensory and physicochemical analysis; 90 fruits were used to extract the pulp (after washing and peeling), which was immediately frozen in liquid nitrogen and then stored at $-80^{\circ} \mathrm{C}$ and used for the nutraceutical evaluation within one month.

GR mango fruit collected from 5 large-scale organized markets (LDM) were immediately analyzed and evaluated; $50 \%$ of GR remaining mango fruit were stored at room temperature $\left(20^{\circ} \mathrm{C}\right)$ for $4-8$ days until they reached MR stage and then were submitted to analysis or were frozen [9].

\subsection{Quality Parameters: Weight, Firmness, Total Soluble Solids, Titratable Acidity, and Decay}

Fruit $(n=60)$ were analyzed at harvest and when they were collected from the 5 large-scale organized distribution markets (GR and MR). Fruit weight was determined using a digital scale. Firmness, expressed in Newton (N), was evaluated with a digital penetrometer (mod. 53205, TR Turoni, Forlì, Italy) incorporating an $8 \mathrm{~mm}$ diameter probe on opposite cheeks of each fruit, after removal of a small piece of peel. A wedge-shaped portion of flesh was removed longitudinally (from the top to the bottom) from each fruit and ten fruit wedges were peeled and juiced. Total soluble solids (TSS) were analyzed by digital refractometer (Palette PR-32, Atago Co. Ltd., Tokyo, Japan) and titratable acidity (TA) was quantified by titration of $10 \mathrm{~mL}$ juice with $0.1 \mathrm{~N} \mathrm{NaOH}$ to $\mathrm{pH} 8.1$ (mod. S compact titrator, Crison Instruments, Barcelona, Spain) and expressed as $\mathrm{g} \mathrm{L}^{-1}$ of citric acid, which is the most representative acid in mango fruit [4]. Fruit were also checked for the presence of decay, the incidence of which was expressed as a percentage.

\subsection{Total Carotenoid Content}

As previously reported, after preliminary carotenoids extraction, total carotenoid content (TCC) was quantified by spectrophotometer [20]. Procedures were carried out on ice and under dim light. Three aliquots of fruit flesh (ca. $5 \mathrm{~g}$ per aliquot) were analyzed. Each aliquot was obtained from 5 fruit for each series (GR or MR); the aliquot was previously ground to a fine powder under liquid nitrogen and then it was mixed for $20 \mathrm{~min}$ with $50 \mathrm{~mL}$ of extracting solvent (hexane/acetone/ethanol, 50:25:25, $v / v / v)$. After dilution with hexane, the organic phase with carotenoids was recovered, and then it was used for analyses. Visible spectra were collected and TCC was evaluated by absorbance at $450 \mathrm{~nm}$. TCC was quantified according to the method of Ritter and Purcell using a molar extinction coefficient 
of $\beta$-carotene of 2505 and was expressed as $\mu \mathrm{g} \beta$-carotene per $\mathrm{g}$ fresh weight (FW). For each ripening stage, 3 biological replicates were used consisting of 5 fruits each.

\subsection{Preparation of the Fruit Extracts}

Ethanolic extracts of flesh fruit were produced as previously described [7]. Three different samples of five fruit for each series, GR or MR, were analyzed. The extracts were used for the total phenolic content and the total antioxidant activity.

\subsection{Total Phenolic Content}

According to Folin and Denis, total phenolic content (TPC) of ethanolic extracts was quantified using the reduction, in alkaline solution, of phosphotungstic-phosphomolybdic acid (Folin-Ciocalteau's reagent) to blue pigments [21]. Quantification was performed by gallic acid (GA) calibration curve, and the results were expressed as mg GA equivalents (GAE) per $100 \mathrm{~g}$ FW. For each ripening stage, 3 biological replicates were used consisting of 5 fruits each.

\subsection{Total Antioxidant Activity}

The total antioxidant activity (TAA) of ethanol extracts was investigated using the ABTS radical cation decolorization assay [22]. Samples were evaluated at five different dilutions, within the assay linearity range. TAA was expressed as $\mu \mathrm{mol}$ Trolox equivalent (TE) per $100 \mathrm{~g}$ FW. For each ripening stage, 3 biological replicates were used consisting of 5 fruits each.

\subsection{Sensory Analysis}

Fruit $(n=15)$ from local grower and imported from abroad were subjected to sensory evaluation at GR and MR stage. The sensory profile was constructed by a semi-trained panel made of 10 judges ( 5 females and 5 males, aged between 25 and 45 years) who, by using commercial fruit, in a few preliminary meetings, generated a list of descriptors [23]. The semi-trained panel is made up of people normally familiar with mango fruit. This type of panel can discriminate differences and communicate their reactions, though the individuals may not have been formally trained; furthermore, a semi-trained panelist judgment is likely to be closer to that of the average consumer [24]. Sensory analysis was focused on appearance ( 2 descriptors), tactile hand feel (1 descriptor), aroma (6 descriptors), flavor (6 descriptors), taste and tactile (5 descriptors) and rheological descriptors, focused on juiciness perceived in the mouth (1 descriptor) [8].

An approximately $50 \mathrm{~g}$ sample was dispensed into a small plastic tray with a 3-digit code on the side and served to the judges [4]. The different descriptors were measured using an eight-point intensity scale where the digit 1 indicates the descriptor absence while the digit 8 indicates the full intensity. Among the judges the order of presentation of the fruit was randomized; water was used to rinse the mouth [5].

\subsection{Statistical Analysis}

Analysis of Variance (ANOVA) was applied to measure differences between mean values of all data using Tukey's multiple comparisons test for $p \leq 0.05$. Statistical software SYSTAT 10 was used for the analysis.

\section{Results and Discussion}

\subsection{Quality Parameters: Weight, Firmness, Total Soluble Solids, Titratable Acidity, and Decay}

Fresh Mediterranean Italian (MedIT) mango fruit showed significantly higher weight in both maturity stages. Indeed, MedIT mango fruit (GR and MR) showed values of $12 \%$ and $25 \%$ higher than imported ones (Figure 1), most likely due to the early harvest of the imported fruit. "Osteen" MedIT mango fruit and the imported fruit showed similar behavior in terms of firmness reduction from GR 
to MR ripen stage, showing a firmness decrease of $75 \%$ and $89 \%$, respectively (Figure 2). MR MedIT "Osteen" mango fruit showed firmness values 2.1 times higher than imported ones; furthermore, imported mango fruit showed a faster ripening from GR and MR ripen stage (Figure 2). GR and MR MedIT mango fruit showed significantly higher values of TSS than the imported ones (Figure 3). Indeed, "Osteen" GR MedIT mango fruit showed TSS values of $48 \%$ higher than imported ones. "Osteen" MR MedIT fresh mango fruit showed similar behavior with TSS values of $38 \%$ higher than imported ones (Figure 3). "Osteen" MedIT mango fruit showed an average TSS value of 1.7 times higher (GR and MR) than imported mango fruit (Figure 3). GR and MR imported mango fruits, showed higher TA values than MedIT mango fruit; in fact, TA values were almost double in both maturity stages (GR and MR) (Figure 4). In any case, firmness, TSS and TA were affected by maturity stages (GR and MR) in all mango fruit (MedIT and imported). Our data confirm that the early harvest of imported mango fruit improves transportability, but negatively affects fruit quality parameters such as firmness, TSS and TA. MR imported mango fruits were affected by flesh disorders, specifically, 30\% of MR "Osteen" imported mango fruits were affected by flesh disorders (browning), losing its marketability (data not shown). Mango imported fruit flesh disorders were probably caused by chilling injuries due to the application of temperature below $10-13^{\circ} \mathrm{C}$ during long transportation and retail storage [24]. Indeed, MedIT mango fruit were not affected by flesh disorders.

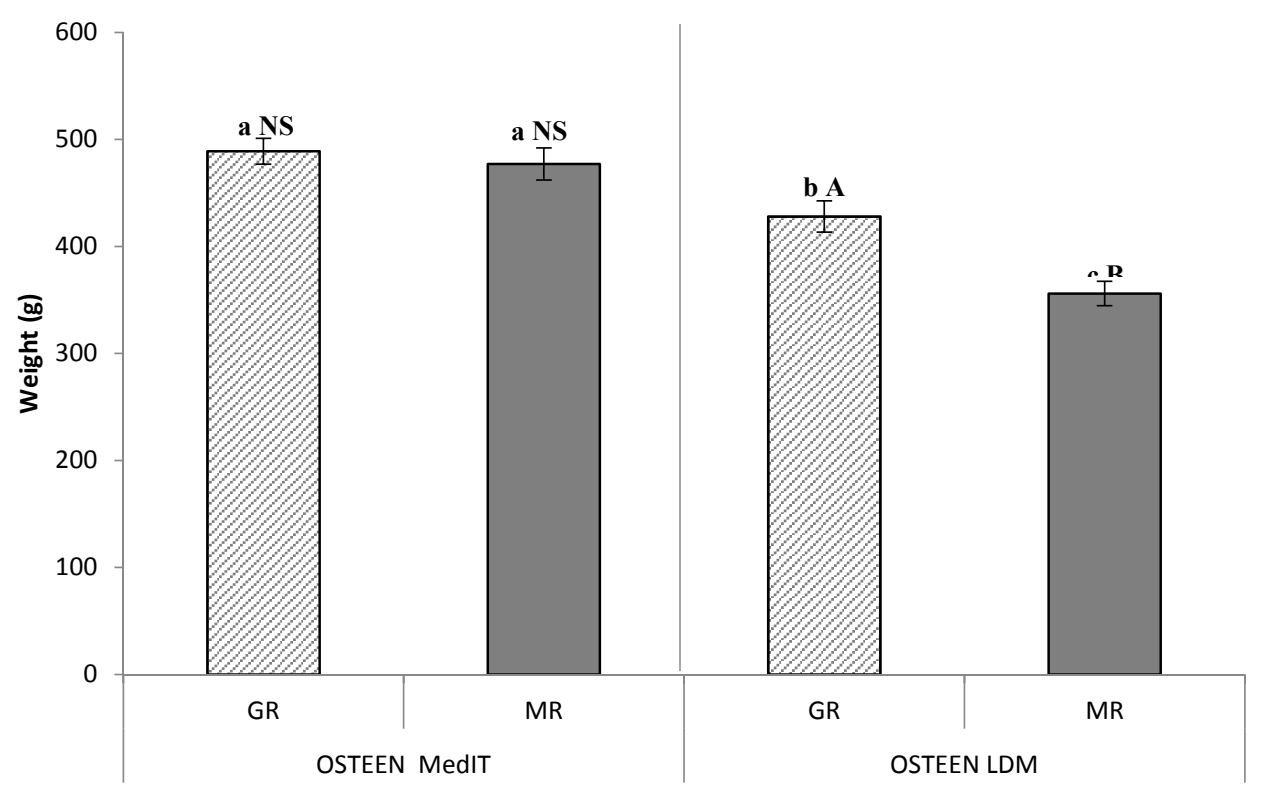

Figure 1. Evolution of fruit weight in green-ripe (GR) and mature-ripe (MR) fresh Mediterranean Italian (MedIT) and imported (LDM) “Osteen" mango fruit. Values represented as mean \pm SE $(n=30)$. Different lowercase letters indicate significant differences between imported and fresh Mediterranean Italian mango fruit (GR and MR). Different uppercase letters indicate significant differences between mature-green (GR) and mature-ripe (MR) stages in the same series, fresh Mediterranean Italian fresh mango fruit or imported (Osteen MedIT or Osteen LDM). 


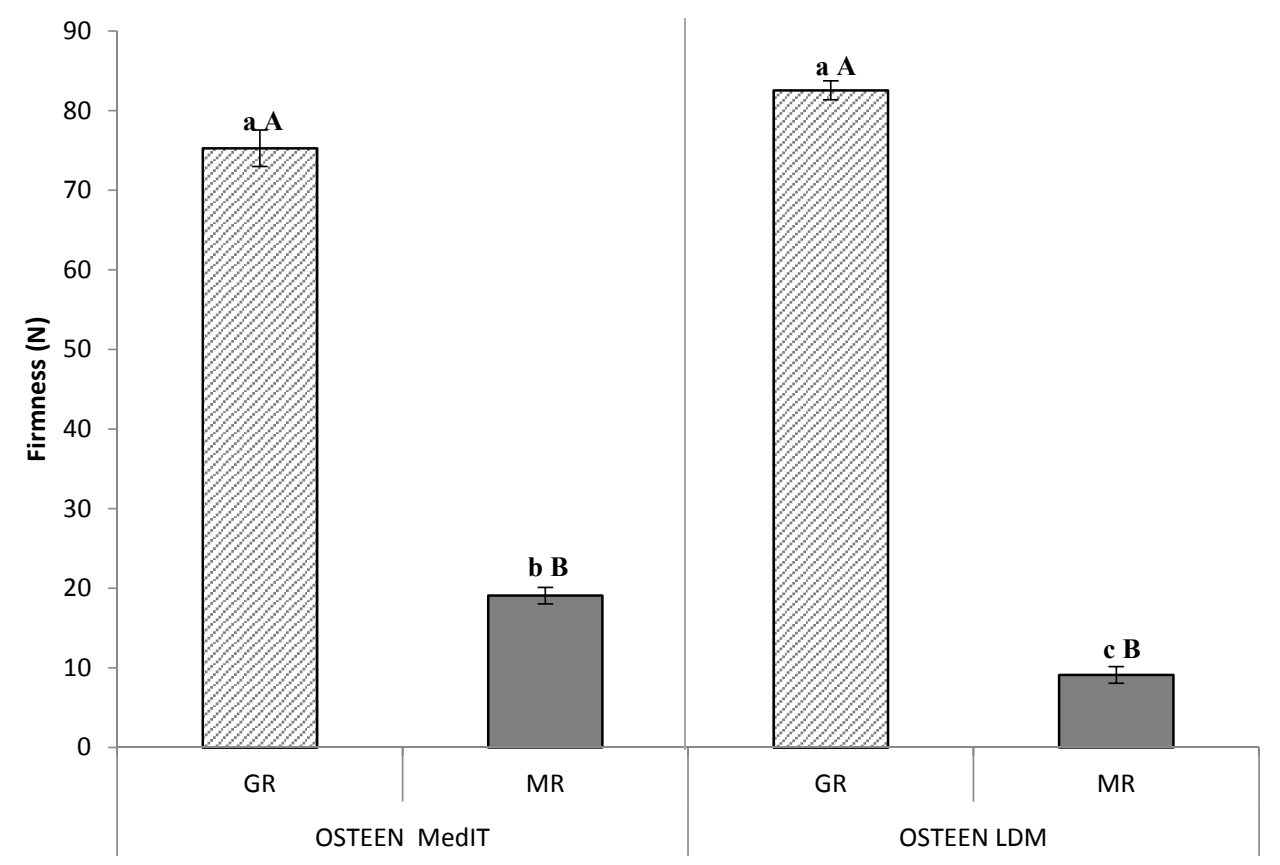

Figure 2. Evolution of fruit firmness in green-ripe (GR) and mature-ripe (MR) fresh Mediterranean Italian (MedIT) and imported (LDM) “Osteen" mango fruit. Values represented as mean \pm SE $(n=30)$. Different lowercase letters indicate significant differences between imported and fresh Mediterranean Italian mango fruit (GR and MR). Different uppercase letters indicate significant differences between mature-green (GR) and mature-ripe (MR) stages in the same series, fresh Mediterranean Italian fresh mango fruit or imported (Osteen MedIT or Osteen LDM).

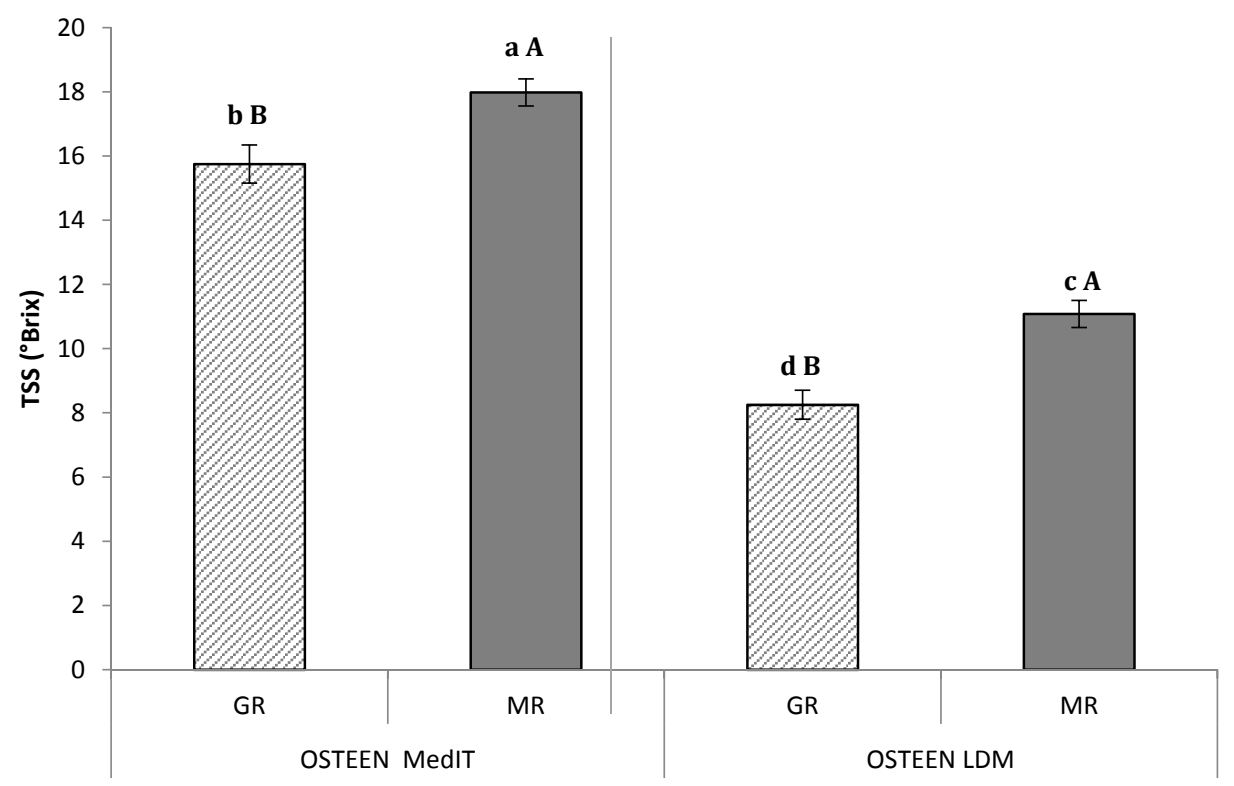

Figure 3. Evolution of Total Soluble Solids (TSS) in green-ripe (GR) and mature-ripe (MR) fresh Mediterranean Italian (MedIT) and imported (LDM) "Osteen" mango fruit. Values represented as mean \pm SE $(n=30)$. Different lowercase letters indicate significant differences between imported and fresh Mediterranean Italian mango fruit (GR and MR). Different uppercase letters indicate significant differences between mature-green (GR) and mature-ripe (MR) stages in the same series, fresh Mediterranean Italian fresh mango fruit or imported (Osteen MedIT or Osteen LDM). 


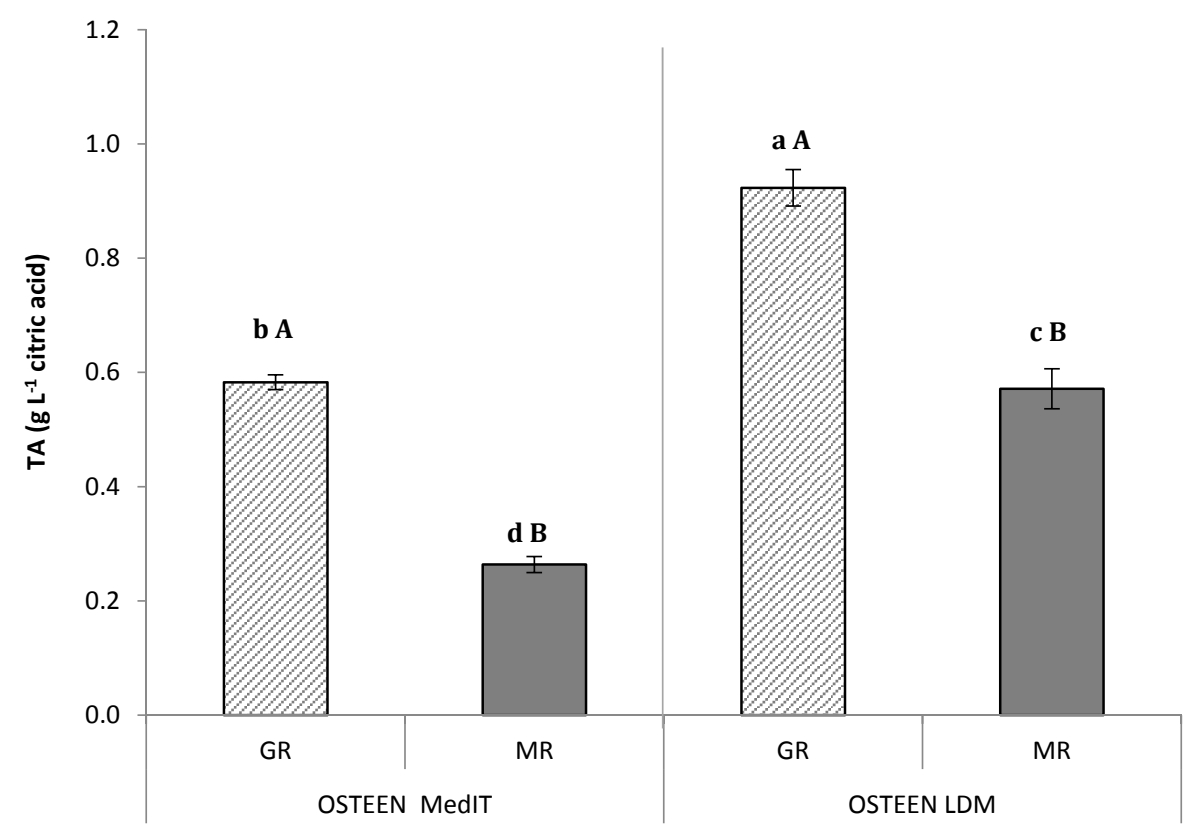

Figure 4. Evolution of Titratable Acidity (TA) in green-ripe (GR) and mature-ripe (MR) fresh Mediterranean Italian (MedIT) and imported (LDM) “Osteen" mango fruit. Values represented as mean \pm SE $(n=30)$. Different lowercase letters indicate significant differences between imported and fresh Mediterranean Italian mango fruit (GR and MR). Different uppercase letters indicate significant differences between mature-green (GR) and mature-ripe (MR) stages in the same series, fresh Mediterranean Italian fresh mango fruit or imported (Osteen MedIT or Osteen LDM).

\subsection{Bioactive Compounds and Antioxidant Properties}

The beneficial effects of plant food consumption may be ascribed also in this case to numerous bioactive compounds [25-27]. Phytochemical content and profile of individual phytochemicals are affected by genotype, ripening stage and storage conditions [8,28].

In this study, TCC in "Osteen" mango fruit changed as a function of both ripening stage (GR and MR) of fresh Mediterranean Italian (MedIT) mango fruit and imported ones, with mean values comparable to previous studies reported for other mango cultivars $[7,28]$. Carotenoid synthesis was higher during ripening at the tree with light exposure. Predictably, MR fruit showed higher TCC values than GR fruit. In particular, MR MedIT mango fruits showed TCC values approximately 10 times higher than the corresponding GR ones. Concerning the imported fruit, the differences were smaller, with TCC of MR fruit being approximately 2 times higher than the corresponding GR ones, MR MedIT mango fruit showed TCC values approximately $65 \%$ higher than imported ones, probably due to a too early harvest of the imported fruit (Table 1).

The evolution of the content in hydrophilic antioxidants, such as polyphenols and vitamin C, during ripening, unlike the evolution in TCC, is more difficult to predict. In fact, during ripening, the quantity of these secondary metabolites is influenced not only by their biosynthesis but also by oxidative conditions induced by light or air exposure. In our experimental conditions, while were no differences between GR and MR imported mango fruit, MR MedIT mango fruit showed higher TPC than the corresponding GR ones (Table 1). Concerning MedIT mango fruit, similar evolution in TPC of Osteen fruits was shown previously [7].

Bioactivity of several phytochemicals has been frequently related to their antioxidant properties, useful for preventing oxidative stress phenomena and influencing important redox-dependent cell functions [29]. Radical scavenging activity, expressed as the TAA value, of the ethanolic extracts of the observed mango fruits was evaluated by ABTS assay. Our results showed a significant variability as a function of the ripening stage: regardless of the origin, MR mango fruit showed TAA values higher 
than the corresponding GR fruits. However, MR MedIT mango fruit showed significantly higher antioxidant properties than imported MR ones (Table 1). For both fruit series, GR and MR, TAA values positively correlated with TPC, according to previously reported data $[7,30,31]$, suggesting the great contribution of polyphenols to the antioxidant properties of mango fruit.

Table 1. Total carotenoid content (TCC), total polyphenolic content (TPC) and Total Antioxidant Activity (TAA) in green-ripe (GR) and mature-ripe (MR) fresh Mediterranean Italian (MedIT) and imported (LDM) "Osteen" mango fruit. Values represented as mean \pm SE $(n=15)$. For each line, different lowercase letters indicate significant differences between the ripening stage mature-green (GR) and mature-ripe (MR) of each mango fruit (fresh Mediterranean Italian or imported); for each column, uppercase letters, within the same series (GR or MR) indicate significantly differences between fresh Mediterranean Italian and imported fruit.

\begin{tabular}{|c|c|c|c|c|c|c|}
\hline & \multicolumn{2}{|c|}{ TCC } & \multicolumn{2}{|c|}{ TPC } & \multicolumn{2}{|c|}{ TAA } \\
\hline & \multicolumn{2}{|c|}{ ( $\mu \mathrm{g} \beta$-Carotene eq per $\mathrm{g}$ of $\mathrm{FW})$} & \multicolumn{2}{|c|}{ (mg GAE per $100 \mathrm{~g}$ of $\mathrm{FW}$ ) } & \multicolumn{2}{|c|}{$(\mu \mathrm{mol}$ TE per $100 \mathrm{~g}$ of $\mathrm{FW})$} \\
\hline & $G R$ & $M R$ & $G R$ & $M R$ & $G R$ & $M R$ \\
\hline OSTEEN MedIT & $1.38 \pm 0.07^{\mathrm{bB}}$ & $13.64 \pm 0.12^{\mathrm{aA}}$ & $16.63 \pm 1.94^{\mathrm{bB}}$ & $28.29 \pm 1.24^{\mathrm{aA}}$ & $93.07 \pm 2.43^{\mathrm{bA}}$ & $195.45 \pm 5.32^{\mathrm{aA}}$ \\
\hline OSTEEN LDM & $6.17 \pm 0.09 \mathrm{bA}$ & $8.93 \pm 0.08^{\mathrm{aB}}$ & $20.39 \pm 0.39^{\mathrm{aA}}$ & $20.11 \pm 1.86^{\mathrm{aB}}$ & $91.49 \pm 1.97^{\mathrm{bA}}$ & $99.90 \pm 2.03^{a B}$ \\
\hline
\end{tabular}

\subsection{Sensory Analysis}

Panelists preferred fresh Mediterranean Italian (MedIT) mango fruit at both maturity stages (Figures 5 and 6); in particular, "Osteen" MedIT mango fruit achieved higher scores in terms of skin color, juiciness, exotic fruit flavor, exotic fruit odor and overall acceptance (Figures 5 and 6).

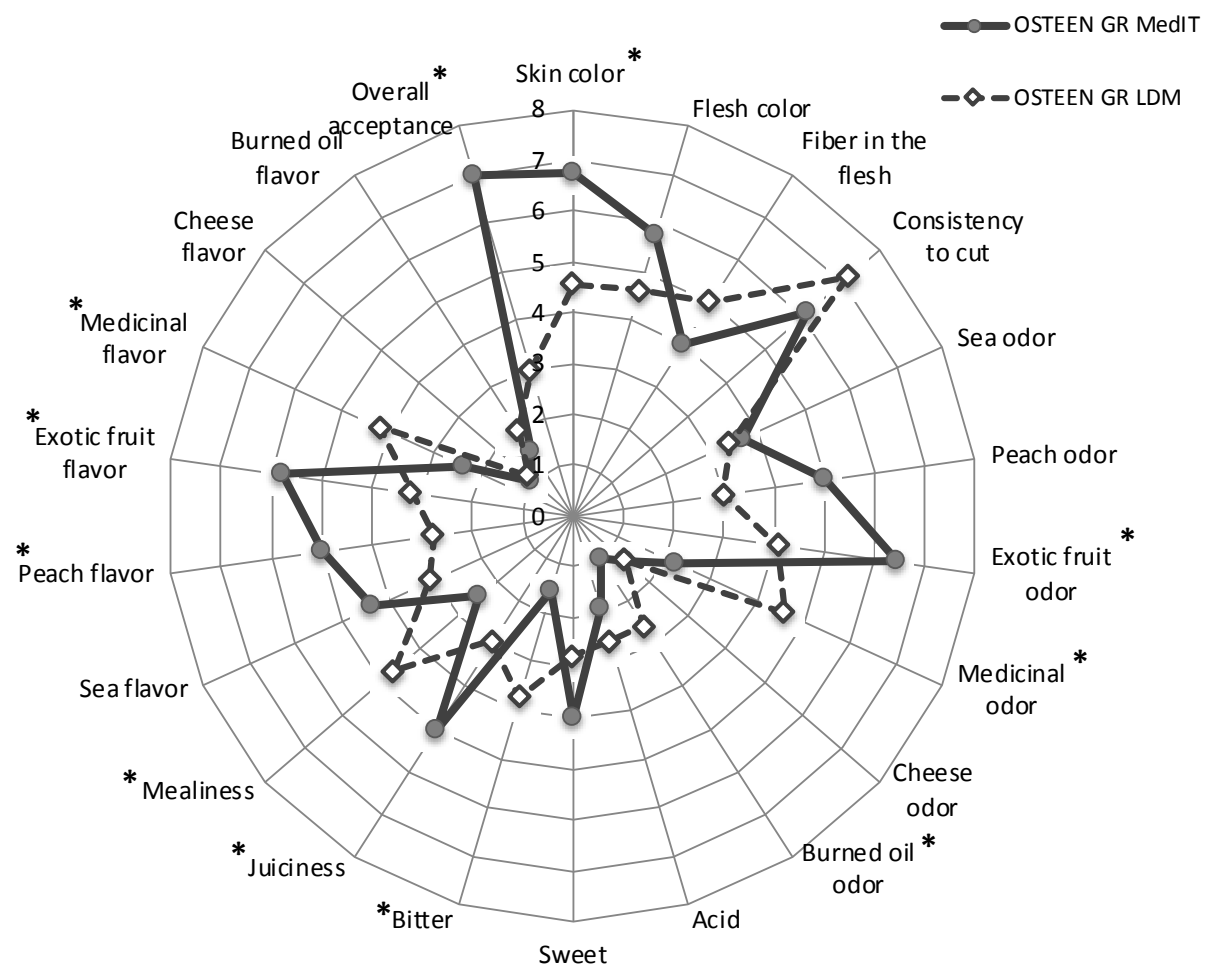

Figure 5. Sensory analysis of mature-green (GR) fresh Mediterranean Italian (MedIT) and imported (LDM) “Osteen" mango fruit. Data are Mean of 15 fruit for each ripening stage. * Indicates significant differences for values (Tukey's test at $p \leq 0.05$ ). 


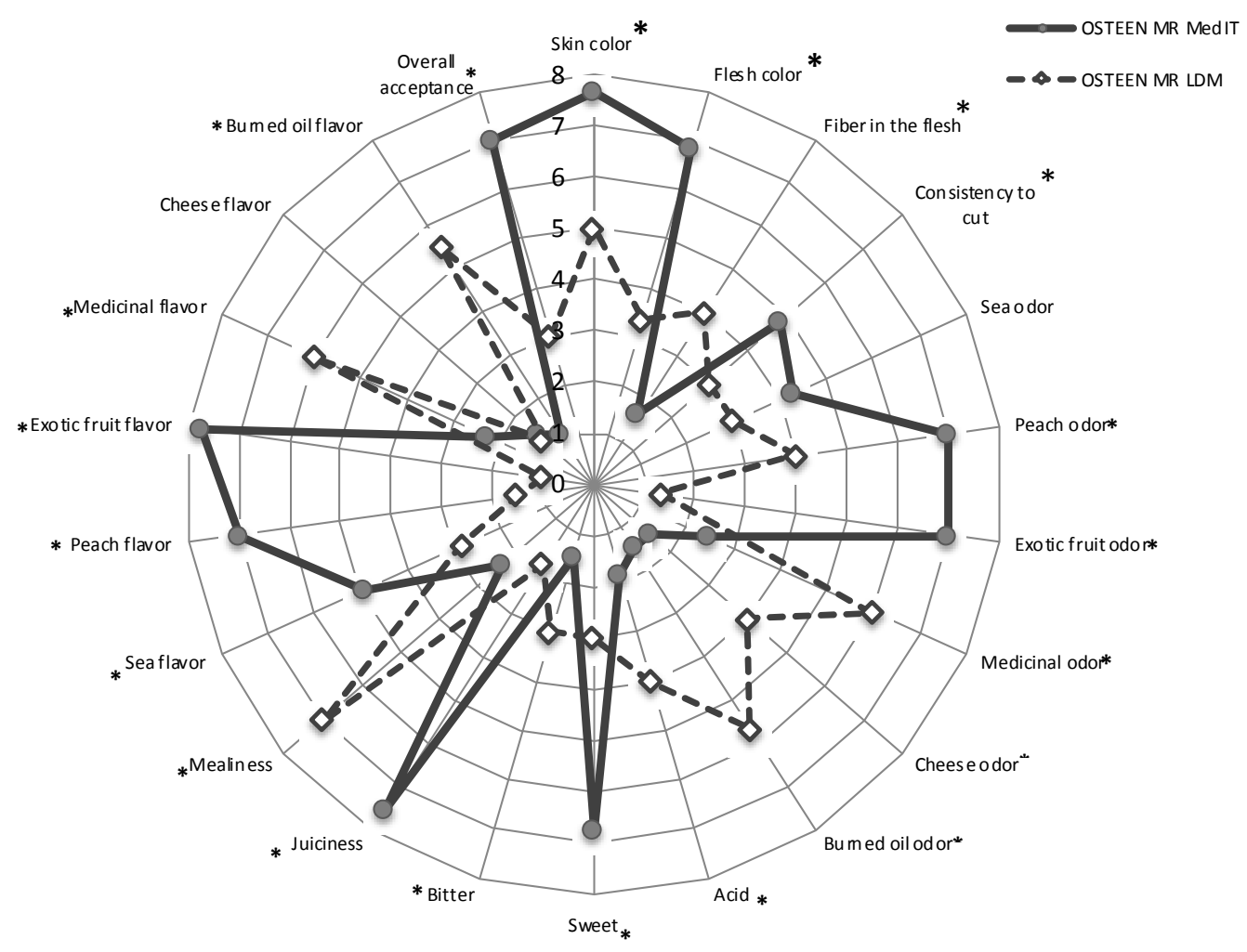

Figure 6. Sensory analysis of mature-ripe (MR) fresh Mediterranean Italian (MedIT) and imported (LDM) “Osteen” mango fruit. Data are Mean of 15 fruit for each ripening stage. * Indicates significant differences for values (Tukey's test at $p \leq 0.05$ ).

GR "Osteen" MedIT mango fruit showed higher scores in most of the descriptors, as well as, skin color, peach flavor, and odor, juiciness, exotic fruit flavor and odor, etc.; and the lowest scores in terms of off-flavor and off-odor (medicinal flavor and odor; burned oil odor), than imported mango fruits (Figure 6).

MR "Osteen" MedIT mango fruit showed higher scores in most of the descriptors, as well as, skin and flesh color, peach flavor, and odor, sweetness, juiciness, exotic fruit flavor and odor, etc.; and the lowest scores in terms of off-flavor and off-odor, than imported mango fruits (Figure 6).

During softening (from GR to MR ripening stage), Osteen peach aroma and tropical fruit increased in both fruit categories (MedIT and imported), but, in any case, MedIT mango fruit demonstrated significantly higher scores (Figures 5 and 6), as shown in "Ataulfo" mango fruit [32]. The specific fruit aroma and flavor perception are due to different volatile compounds intensity and range synthesized during ripening. This characteristic aroma and flavor affect consumer preference and acceptance [32]. Juiciness had the lowest score of high flesh firmness, increasing from GR to MR ripening stage in MedIT and imported mango fruit; but, in any case, MedIT mango fruit showed significantly higher scores and was preferred by the panelists (Figures 5 and 6). The loss of fruit juiciness during softening is due to the pectin polysaccharide metabolism. The reduction of its capacity to retain water leads to an increase in the perception of juiciness in fruit tissue [33,34]. For that reason, panelists perceived higher juiciness in the lowest fruit flesh firmness in both categories (imported and MedIT) (Figures 5 and 6). Polysaccharides cell wall breakdown can also reduce fibrous texture due to the reduction of polysaccharide chains in fruit flesh [33,34]. For that reason, GR MedIT and imported mango fruit showed the highest scores in terms of presence of fiber in the flesh (Figure 5); in any case, GR and MR MedIT mango fruit showed the lowest scores and were preferred by the panelists (Figures 5 and 6 ).

MR mango imported fruit showed higher scores in terms of off-flavor (medicinal flavor and burned oil flavor) and off-odor (medicinal odor, burned oil odor), than the MedIT ones (Figure 6). 
"Osteen", mango imported fruit showed a noticeable increase in terms of medicinal odor, burned oil odor, medicinal flavor and burned oil flavor between GR and MR stage (Figures 5 and 6).

Sensory analysis was consistent with the analytical measurements, namely that the higher TSS values of MR MedIT mango fruit were also perceived by the panelists. MR MedIT mango fruit quality parameters measured were in line with the scores obtained in terms of overall acceptance.

\section{Conclusions}

Our study showed that fresh Mediterranean Italian mango fruit were preferred by the panelists, despite that fact that the fruit did not come from their original tropical countries; this is probably because imported mango fruit were collected before full flavor development. Furthermore, our data confirm the high potential of Southern Italy for mango fruit production that reaches high quality also under the Mediterranean climate.

Fresh Mediterranean Italian mango fruit demonstrated higher size, higher levels of TSS and the best scores in terms of taste in both maturity stages (GR and MR). In particular, the data obtained on MR fresh Mediterranean Italian mango fruit showed that ripening is strictly correlated to the sensory perception of panelists and could affect consumer preferences and potentially choices. MR fresh Mediterranean Italian fruit showed the highest pomological and sensorial traits, together with interesting nutraceutical values suitable for short supply chains. Fruit harvested at commercial ripening (GR) and matured after harvest appear firmer and can withstand prolonged storage and shipping. Moreover, as expected, our results demonstrated that the harvest time significantly affects the final fruit quality; imported mango fruit grown under tropical climate needs an advanced harvest to reach EU market in acceptable condition, while fresh Mediterranean Italian mango fruit can be collected also at ready-to-eat maturity (MR) stage and reach the EU markets in higher quality conditions in terms of taste and nutraceutical value, due to the shorter distance to the European markets.

Sensory experiences play a prevailing role in consumer satisfaction, and as a consequence, the acceptance of tropical fruit in EU markets. Our study brings out some important factors dealing with the relationship between taste and product evaluation or acceptance. Until now, a large number of consumers are still unfamiliar with Italian fresh mango fruit, grown in the Mediterranean climate, and for that reason, producers and retailers should promote an educational initiative to inform people about Mediterranean Italian tropical fruit production and to improve the large potential for the fresh mango market in Italy. Mango fruit production in Southern Italy offers interesting export potential for high-quality fresh fruit, mainly due to its closeness to other EU countries.

Author Contributions: All authors have equally contributed with their knowledge to the present article. Conceptualization, G.L.; Methodology, G.L., V.F., G.S., and C.G.; Data Gathering and Preparation, G.L., C.G., P.I., and G.S.; Writing-Original Draft Preparation, G.L., C.G., and V.F.; Writing-review and editing, G.L and G.S; Supervision, G.L., and V.F. All authors have read and agreed to the published version of the manuscript.

Funding: This research received no external funding.

Conflicts of Interest: The authors declare no conflict of interest.

\section{References}

1. FAO_Food and Agriculture Organization of the United Nations. FAO Statistics; FAO: Rome, Italy, 2016; Available online: http://faostat.fao.org/ (accessed on 17 October 2018).

2. Tharanathan, R.N.; Yashoda, H.M.; Prabha, T.N. Mango (Mangifera indica L.), The king of fruits-An overview. Food Rev. Int. 2006, 22, 95-123. [CrossRef]

3. Sortino, G.; Caviglia, V.; Liguori, G.; De Pasquale, C.; Gianguzzi, G.; Farina, V. Quality Changes of Tropical and Subtropical Fresh-Cut Fruits Mix in Modified Atmosphere Packaging. Chem. Eng. Trans. 2017, 58, 397-402.

4. Farina, V.; D'Asaro, A.; Mazzaglia, A.; Gianguzzi, G.; Palazzolo, E. Chemical-physical and nutritional characteristics of mature-green and mature-ripe 'Kensington Pride' mango fruit cultivated in Mediterranean area during cold storage. Fruits 2017, 72, 221-229. [CrossRef] 
5. Mossad, A.; El Helew, K.K.M.; Elsheshtawy, H.E. Mass modelling by dimension attributes for Mango (Mangifera indica cv. Zebdia) relevant to post-harvest and food plants engineering. Agric. Eng. Int. CIGR J. 2016, 18, 219-229.

6. Maldonado-Celis, M.E.; Yahia, E.Y.; Bedoya, R.; Landázuri, P.; Loango, N.; Aguillón, J.; Restrepo, B.; Guerrero Ospina, J.C. Chemical Composition of Mango (Mangifera indica L.) Fruit: Nutritional and Phytochemical Compounds. Front. Plant Sci. 2019, 10, 1073. [CrossRef]

7. Gentile, C.; Di Gregorio, E.; Di Stefano, V.; Mannino, G.; Perrone, A.; Avellone, G.; Farina, V. Food quality and nutraceutical value of nine cultivars of mango (Mangifera indica L.) fruits grown in Mediterranean subtropical environment. Food Chem. 2019, 277, 471-479. [CrossRef] [PubMed]

8. Liguori, G.; Sortino, G.; Gianguzzi, G.; Inglese, P.; Farina, V. Evaluation of quality attributes and consumer preference of fresh or imported mangoes in Italy. AIMS Agric. Food 2018, 3, 426-440.

9. Nunes, C.N.; Emond, J.P.; Brecht, J.K.; Dea, S.; Proulx, E. Quality curves for mango fruit stored at chilling and non chilling temperatures. J. Food Qual. 2007, 30, 104-120. [CrossRef]

10. Medlicott, A.P.; Reynolds, S.B.; New, S.W.; Thompson, A.K. Harvest maturity effects on mango fruit ripening. Trop. Agric. 1988, 65, 153-157.

11. Vanoli, M.; Grassi, M.; Spinelli, L.; Torricelli, A.; Rizzolo, A. Quality and nutraceutical properties of mango fruit: Influence of cultivar and biological age assessed by Time-resolved Reflectance Spectroscopy. Adv. Hortic. Sci. 2018, 32, 407-420.

12. Kalra, S.K.; Tandon, D.K.; Singh, B.P. Handbook of fruit science and technology. In Production, Composition, Storage and Processing; Salunkhe, D.K., Kadam, S.S., Eds.; Marcel Dekker Inc.: New York, NY, USA, 1995; pp. 123-170.

13. FAO-Food and Agriculture Organization of the United Nations. Medium-Term Prospects for Agricultural Commodities; FAO Commodities and Trade Technical Papers No 1; FAO: Rome, Italy, 2003.

14. Sabbe, S.; Verbeke, W.; Van Damme, P. Familiarity and purchasing intention of Belgian consumers for fresh and processed tropical fruit products. Br. Food J. 2008, 110, 805-818. [CrossRef]

15. Sabbe, S.; Verbeke, W.; Van Damme, P. Confirmation/disconfirmation of consumers' expectations about fresh and processed tropical fruit products. Int. J. Food Sci. Technol. 2009, 44, 539-551. [CrossRef]

16. Akhtar, S.; Mahmood, S.; Naz, S.; Nasir, M.; Saultan, M.T. Sensory evaluation of mangoes (Mangifera indica L.) Grown in different regions of Pakistan. Pakistan J. Bot. 2009, 41, 2821-2829.

17. Calatrava-Requena, J.; González-Roa, M.C.; Guirado-Sánchez, E. Taste testing and consumer preferences for mango cultivars: A panel analysis. Acta Hortic. 2013, 992, 579-585. [CrossRef]

18. Cheema, G.S.; Dani, P.G. Report on export of mango to Europe in 1932-3. Bombay Dep. Agric. Bull. 1934, 170, 259-325.

19. Palapol, Y.; Ketsa, S.; Stevenson, D.; Cooney, J.M.; Allan, A.C.; Ferguson, I.B. Colour development and quality of mangosteen (Garcinia mangostana L.) fruit during ripening and after harvest. Postharv. Biol. Technol. 2009, 51, 349-353. [CrossRef]

20. Gentile, C.; Reig, C.; Corona, O.; Todaro, A.; Mazzaglia, A.; Perrone, A.; Farina, V. Pomological Traits, sensory Profile and Nutraceutical Properties of Nine Cultivars of Loquat (Eriobotrya japonica Lindl.) Fruits Grown in Mediterranean Area. Plant Foods Hum. Nut. 2016, 71, 330-338. [CrossRef]

21. Singleton, V.L.; Rossi, J.A. Colorimetry of total phenolics with phosphomo- lybdic-phosphotungstic acid reagents. Am. J. Enol. Vitic. 1965, 16, 144-158.

22. Miller, N.J.; Rice-Evans, C.A. Spectrophotometric determination of anti-oxidant activity. Redox Rep. 1996, 2, 161-171. [CrossRef]

23. Ruiz-Capillas, C.; Moral, A. Use of semitrained panel members in the sensory evaluation of hake (Merluccius merluccius L.) analyzed statistically. J. Food Qual. 2003, 26, 181-195. [CrossRef]

24. Liguori, G.; Inglese, P.; Corona, O.; Farina, V. Effects of 1-Methylcyclopropene on postharvest quality traits, antioxidant activity and ascorbic acid content of mature-ripe mango fruits. Fruits 2017, 72, 238-246. [CrossRef]

25. Gentile, C.; Perrone, A.; Attanzio, A.; Tesoriere, L.; Livrea, M.A. Sicilian pistachio (Pistacia vera L.) nut inhibits expression and release of inflammatory mediators and reverts the increase of paracellular permeability in IL-1 $\beta$-exposed human intestinal epithelial cells. Eur. J. Nutr. 2015, 54, 811-821. [CrossRef] [PubMed] 
26. Mannino, G.; Perrone, A.; Campobenedetto, C.; Schittone, A.; Margherita Bertea, C.; Gentile, C. Phytochemical profile and antioxidative properties of Plinia trunciflora fruits: A new source of nutraceuticals. Food Chem. 2020, 307, 125515. [CrossRef]

27. Morand, C.; Tomás-Barberán, F.A. Contribution of plant food bioactives in promoting health effects of plant foods: Why look at interindividual variability? Eur. J. Nutr. 2019, 58, S13-S19. [CrossRef] [PubMed]

28. Shivashankara, K.S.; Isobe, S.; Al-Haq, M.I.; Takenaka, M.; Shiina, T. Fruit antioxidant activity, ascorbic acid, total phenol, quercetin, and carotene of Irwin mango fruits stored at low tempertaure after high electric field pretreatment. J. Agric. Food Chem. 2004, 52, 1281-1286. [CrossRef]

29. Gentile, C.; Allegra, M.; Angileri, F.; Pintaudi, A.M.; Livrea, M.A.; Tesoriere, L. Polymeric proanthocyanidins from Sicilian pistachio (Pistacia vera L.) nut extract inhibit lipopolysaccharide-induced inflammatory response in RAW 264.7 cells. Eur. J. Nutr. 2012, 51, 353-363. [CrossRef]

30. Liu, F.X.; Fu, S.F.; Bi, X.F.; Chen, F.; Liao, X.J.; Hu, X.S.; Wu, J.H. Physico- chemical and antioxidant properties of four mango (Mangifera indica L.) cultivars in China. Food Chem. 2013, 138, 396-405. [CrossRef]

31. Sulaiman, S.F.; Ooi, K.L. Polyphenolic and vitamin C contents and antioxidant activities of aqueous extracts from mature-green and ripe fruit fleshes of mangifera SP. J. Agric. Food Chem. 2012, 60, 11832-11838. [CrossRef]

32. De Cassia Mirela Resende Nassur, R.; Gonzalez-Moscoso, S.; Crisosto, M.G.; de Oliveira Lima, L.C.; de Barros Vilas Boas, E.V.; Crisosto, C.H. Describing Quality and Sensory Attributes of 3 Mango (Mangifera indica L.) cultivars at 3 ripeness stages based on firmness. J. Food Sci. 2015, 80, 2055-2063.

33. Brummell, D.A.; Dal Cin, V.; Lurie, S.; Crisosto, C.H.; Labavitch, J.M. Cell wall metabolism during the development of chilling injury in cold-storage peach fruit: Association of mealiness with arrested disassembly of cell wall pectins. J. Exp. Bot. 2004, 55, 2041-2052. [CrossRef]

34. Goulao, L.F.; Oliveira, C.M. Cell wall modifications during fruit ripening: When a fruit is not the fruit. Trends Food Sci. Technol. 2008, 19, 4-25. [CrossRef]

(C) 2020 by the authors. Licensee MDPI, Basel, Switzerland. This article is an open access article distributed under the terms and conditions of the Creative Commons Attribution (CC BY) license (http://creativecommons.org/licenses/by/4.0/). 